\title{
Effect of Teaching Program on Nurses' Knowledge and Practice Regarding Measuring End-Carbon Dioxide by Capnography at Critical Care Units
}

\author{
Warda Kamel Mohamed, Mona Aly Mohamed, Mona Abd Elaziem Ahmed. \\ 1. Nurse Specialist at Assuit University Hospital, Egypt. \\ 2. Assistant Prof. of Critical Care and Emergency Department, Faculty of Nursing, Assuit University, Egypt. \\ 3. Lecture of Critical Care and Emergency Department, Faculty of Nursing, Assuit University, Egypt.
}

\begin{abstract}
Carbon dioxide is a product of the body's 'metabolism. Capnography provides an excellent picture of the respiratory process. Aim: To evaluate the effect of Teaching Program of Nurses' knowledge and practice regarding measuring End-Carbon dioxide by capnography in critical units at Assiut University Main Hospital. Design: A Quasi experimental was used. Setting: The study was carried in intensive care and major operation units at Assiut University Main Hospital. Subjects: All available nurses in Intensive care and major operation units about (60) nurses. Tools: Two tools were utilized to collect data, Tool (1): Knowledge Assessment tool, Tool (2): nurses' observational check list, Method: tow time nurses observed by the researcher before and after the teaching program, The researcher used preparatory, implementation and evaluation phases to implement study. Results: The total nurses' knowledge score improved, There was good improvement with highly significant difference related to knowledge and practice of teaching program. Conclusion: The majority of nurses had good level knowledge and practice toward measuring End-Carbon dioxide by capnography after applying teaching program. Recommendations: provide teaching and training program for nurses regarding measuring End-Carbon dioxide by capnography.
\end{abstract}

\section{Keywords: Teaching Program \& Measuring End-Carbon Dioxide by Capnography.}

\section{Introduction}

Critical care nurses should have knowledge and practice to provide care for patients undergoing mechanical ventilation to ensure optimal patient outcomes (Sheila \& et al., 2017).

In spontaneous breathing, as lung inflation progresses, pulmonary stretch receptors behave as sensors that inform adequate inspiratory volume and "turn off" inspiration Intubation is a common lifesaving intervention in the emergency department when a patient is unable to maintain a patent airway, adequate gas exchange or both (Morton \& Fontaine, 2018).

The initial use of capnography during resuscitation was initially proposed by the International Liaison Committee on Resuscitation in 2010, and since 2015 it is becoming a standard of care in advanced highquality cardiopulmonary resuscitation among the several advantages of waveform capnography during cardiopulmonary resuscitation emphasized in current resuscitation guidelines, but one of its most important roles is to monitor ventilation rate, helping to avoid overventilation (Leturiondo \& et al., 2019).

Mechanical ventilation is the process of using machine that facilitates the transport of oxygen and carbon dioxide between the atmosphere and the alveoli for the purpose of enhancing pulmonary gas exchange (Urden \& et al., 2016).

Complications of mechanical ventilation are often it carries potential including pneumothorax, airway injury, alveolar damage, and ventilator-associated pneumonia (Joanne \& Charlton, 2018).

Capnography provides a means to assess alveolar ventilation, the integrity of the airway and ventilatory function by measuring the partial pressure of exhaled carbon Dioxide throughout the breathing cycle (Jonathan \& et al., 2013).

The role of non-invasive ventilation in the elderly: is the first-choice ventilatory technique in some diseases (cardiogenic pulmonary edema, immunosuppression of different origin, neuromuscular disease without severe bulbar impairment, obesity hypoventilation syndrome and chest wall deformity) the advantage of non-invasive ventilation is to offer the same physiological effects of IMV delivered via ETI (Scala, 2016).

In order to standardize the quality of cardiopulmonary resuscitation cardiopulmonary resuscitation and simultaneous measuring, certain mechanical or physiological parameters are considered, Discovery of positive relationship between the cardiac output and end-tidal carbon dioxide (Craig \& Brian, 2017).

\section{Significant of study}

In 2016 the number of patients admitted in critical care ICUs was about (351) patients and (500) patients of major operations units, about more than $50 \%$ of them uses capnography at ICU and $90 \%$ of major 
operations patient connected to MV

(Assuit

University Hospital Records, 2017).

\section{Aim of the study}

- aim of this study was to evaluate the effect of Teaching Program of Nurses' Knowledge and practice Regarding measuring End-Carbon dioxide by capnography in intensive care and major operation units at Assiut University Main Hospital.

\section{Research Hypotheses}

- There was a statistical significance difference between posttest practice score to the pretest practice score following implementation of teaching program.

- There was a statistical significance difference between posttest Knowledge score to the pretest Knowledge score following implementation of teaching program.

- A positive relation was existed between knowledge and practice score obtained by critical care nurses receiving teaching program.

\section{Subject \& Method}

\section{Research design}

A quasi experimental research design

Study variable

- The independent variable was the teaching program

- The dependent variable was the nurse's knowledge and practice about measuring End-Carbon dioxide by Capnography.

Setting

-The study was carried out at general intensive care, trauma care and major operation units at Assiut University Main Hospital.

\section{Sample}

-A convenience sample of all Nurses staff working in selected setting (60 nurses) Were included in the study:

General intensive care: 20

Trauma care unit: 20

Major operation unit: 20

Tools of the study

Two tools were used in this study:-

Tool(1): Nurses' Knowledge Assessment tool

This tool was developed by the researcher after review related literature to assess nurses' knowledge related to measuring End-Carbon dioxide by Capnography,

Part 1:- socio-demographic data: It was sociodemographic characteristic include $(7$ closed ended questions), nurses' code, age, sex, work place, years of experience, qualification and their attendance of related course training program about measuring End-Carbon dioxide by Capnography.
Part 2:- Structure Interview Questionnaire sheet: -It was conducted to assess the need for teaching program it was in Arabic language and to evaluate it by using questions: It consisted of multiple choice (19) questions, true or false (5) questions, discuss (3) questions and list (3) questions, all questions (30) of 90 degree had three alternative answers:

Score value of nurses' knowledge

\begin{tabular}{|c|c|}
\hline Items & Score \\
\hline $\begin{array}{c}\text { in complete corrected } \\
\text { answer }\end{array}$ & 1 \\
\hline $\begin{array}{c}\text { complete corrected } \\
\text { answer }\end{array}$ & 2 \\
\hline incorrect answer & 0 \\
\hline Total answer & 90 \\
\hline
\end{tabular}

Total score of nurses' knowledge was judged and calculated as Follows.

\begin{tabular}{|c|c|}
\hline Items & Score \\
\hline less than(50 degree) & poor: $<50 \%$ \\
\hline from(50 to 75 degree) & Moderate:50 \%- $<75 \%$ \\
\hline more than(75 degree) & Good: $75 \%$ and more \\
\hline
\end{tabular}

The knowledge score based on statistical analysis according to $\mathrm{W} \mathrm{H}$ O Score: less than (50 degree) poor: $<50 \%$, from (50 to 75 degree) Moderate: $50 \%$ $<75 \%$ more than(75 degree) Good: $75 \%$ and more (Noor \& et al., 2016). That cover the following areas: anatomy and physiology of respiratory system, Knowledge about carbon dioxide, Knowledge of capnography device, Capnography verses of Arterial blood gas, capnography and Return of Spontaneous Circulation, Signs and symptoms were observed, Nursing precautions, Instructions of capnography device nurse's Roles of intubation, the capnography waveform phases, Complications of carbon dioxide and Principles of capnography device .

Tool II: Assessment of nurses' observational check list

This tool was consist of observational checklist form was developed by the researcher to assess the practice of the nurses. This tool was used before and after the program to evaluate the effectiveness of the training program on the nurses' practice:

\section{Procedure}

-Hand hygiene

-Preparer Equipment

-Obtain order for continuous measuring with capnography.

-Assess for proper functioning of capnography

-Connect capnography into the appropriate patient cable into display monitor, and turn on instrument

-Perform calibration

-If the patient is not intubated, apply pectco 2 nasal cannula and connect to capnography. 
-For intubated patients, assemble airway adapter, sensor, and display monitor and connect to the patient circuit

-Ensure that the light source is on top of the circuit

-Set appropriate alarms. Alarm limits should in cloud respiratory rate, apnea default, high and low petco2, and minimal levels of inspiratory $\mathrm{CO} 2$

-Discard supplies

-Hand hygiene

Every step evaluated before and after teaching program as follow the total score of Assessment of nurses' observational check list was: calculated as follows:

Score value of nurses' practice

\begin{tabular}{|c|c|}
\hline Items & Score \\
\hline Done & 1 \\
\hline Not done & 0 \\
\hline Total degree & 12 \\
\hline
\end{tabular}

Total score of nurses' practice was judged and calculated based on statistical Analysis as follows.

\begin{tabular}{|c|c|}
\hline Items & Score \\
\hline less than(12 degree) & Poor : $<50 \%$ \\
\hline from(12 to 18 degree) & Fair:50 \%- $<75 \%$ \\
\hline more than(18 degree) & Good:75\% and more \\
\hline
\end{tabular}

Method of data collection

Data was collected in three phases

\section{Preparatory phase}

- Permission to conduct the study obtained from the hospital responsible authorities, after explaining the aim and nature of the study.

- The tools (I) developed by the researcher based on the relevant literature reviewing.

- The developed tools were tested for clarity and reliability by 7 experts in the field of the study and the necessary modifications were done.

2. Content validity

- Three tools were developed by the researcher reviewed by a panel of five experts in medical surgical, critical care and emergency nursing specialties for ensuring content validity and reliability. Based on the experts' opinions responses, the researchers developed the final validated form of the tools.

\section{Pilot study}

- It was conducted on $10 \%$ (15) of sample in selected setting to evaluate the applicability and clearly of tools, it was served to estimate the time required to fill the form, The reliability was tested for tool 1 and 2 by using Cronbach's alpha (tau-equivalent reliability) coefficient $(r=0.827,0.859$ respectively) which its internal consistency "Good", The reliability was tested for tool one (knowledge assessment tool) and was $93.3 \%$ poor level and tool two (practice assessment tool) and was $95.3 \%$ poor level
- Then tools were modified according to the result of pilot study.

\section{Ethical consideration}

1-Research proposal was approved from Ethical Committee in the Faculty of Nursing.

2- There was no risk for study subject during application of the research

3- The study followed common ethical principles in clinical research

4- Written consent was obtained from nurses that were willing to participate in the study, after explaining the nature and purpose of the study.

5- Nurses were assured that the data of this research was used only for the purpose of research.

6- Confidentiality and anonymity was assured.

7- Nurses had the right to refuse to participate and or withdraw from the study without any rational any time

Phase II :( Implementation phase)

_All nurses were met and the purpose and importance of the study was explained, the approval for participation was secured from each nurse.

_ Questionnaire sheet was handed to all participant nurses to fill it before teaching program implementation to evaluate the theoretical knowledge, needs and collected by researcher, the time for the completion of the questionnaire sheet was ranged from 5-15min.

Construction of teaching program

_The teaching program was developed by the researcher based on the previous assessment of the nurse's knowledge about measuring End-Carbon dioxide by Capnography.

_Teaching booklet was revised and modified based on the expertise comments. It was written in Arabic using simple language with illustration.

_ the program was implemented in head nurses' room in intensive care units (ICU) at Assiut university hospital main as following: general ICU, trauma ICU and operative room .Nurses divided into groups according to work status.

Implementation of program

The program was implemented for ten subgroups of nurses all groups were exposed to four sessions in addition to preliminary one.

Preliminary session: in this session the researcher met the participants and explained the objectives, contents and the methods of teaching program (45 minutes), 10 minutes for revision and five minute for summary

Session 1 included: Anatomy and physiology of respiratory tract, Knowledge about carbon dioxide, Knowledge Of capnography device and Capnography verses of blood gas.

(45 minutes) 
Session 2 included: signs and symptoms respiratory distress patients and types and its complications hyper ventilated, hypo ventilated, hypercapnia and hypocapnia patients. (45 minutes)

Session 3 included: Capnography and return of spontaneous circulation, Signs and symptoms were observed, nursing precautions about capnography, Instructions of capnography device (45 minutes).

\section{Session 4 included:}

Recognize nurse's Roles of intubation, capnography waveform phases, Complications of carbon dioxide and Principles of capnography device (45 minutes).

-Group discussion was encouraged with continuous feedback to ensure understanding and achievement of the specific objective of the program.

-An open channel of communication was established between the researcher and the nurses to answer any question reinforce the gained information and correct actions.

-In the last session, the researcher summarized and emphasized the important points.

-Each nurse demonstrated and re-demonstrated the steps individually and completely performed the steps on capnography device.

\section{Evaluation of program}

The evaluation of program was carried out immediately after application of the program using the pre-posttest study tools one(questionnaire about nurses knowledge) and two on(observational check list nurses' practice about measuring ) in order to test the effectiveness of the program on nurses' knowledge and practice.

Data was collected by the researcher during approximately eight months from March 2018 to October 2018

\section{Statistical analysis}

The data obtained had reviewed, prepared for computer entry, coded, analyzed and -tabulated.

- Descriptive statistics (frequencies and percentages, mean and standard deviation, i.e.) were done using computer program (SPSS) version (24).

- Independent sample T-test, Chi-square and Oneway-ANOVA tests used in the relationship between pre-study and post-study groups' knowledge and practice.

- It's considered significant when P. value less than (0.05).

\section{Results}

Table (1) : Distribution of the studied group nurses regarding their socio-demographic data $N=60$.

\begin{tabular}{|c|c|c|}
\hline \multirow{2}{*}{ Items } & \multicolumn{2}{|c|}{ Study Group } \\
\hline & $\mathrm{N}=60$ & $\%$ \\
\hline \multicolumn{3}{|l|}{ Age: } \\
\hline $20 \mathrm{Y}$ to $<35 \mathrm{Y}$ & 57 & 95.0 \\
\hline $35 \mathrm{Y}$ to $<50 \mathrm{Y}$ & 3 & 5.0 \\
\hline Mean \pm SD & \multicolumn{2}{|c|}{$26.1 \pm 5.1$} \\
\hline Range & \multicolumn{2}{|c|}{$20.0-46.0$} \\
\hline \multicolumn{3}{|l|}{ Working place: } \\
\hline Major operation & 20 & $33.33^{\prime}$ \\
\hline General ICU & 20 & $33.33^{\prime}$ \\
\hline Critical Care Unit & 20 & $33.33^{\prime}$ \\
\hline \multicolumn{3}{|l|}{ Gender: } \\
\hline Female & 52 & 86.7 \\
\hline Male & 8 & 13.3 \\
\hline \multicolumn{3}{|l|}{ Educational Level: } \\
\hline Nursing Diploma & 10 & 16.7 \\
\hline Nursing Technician Institute & 31 & 51.7 \\
\hline Bachelor of Nursing & 11 & 18.3 \\
\hline Institute of Technical healthy & 8 & 13.3 \\
\hline \multicolumn{3}{|l|}{ Years of experience: } \\
\hline$<1 \mathrm{Y}$ & 7 & 11.7 \\
\hline $1 \mathrm{Y}$ to $<5 \mathrm{Y}$ & 41 & 68.3 \\
\hline $5 \mathrm{Y}$ to $<10 \mathrm{Y}$ & 1 & 1.7 \\
\hline$\geq 10 \mathrm{Y}$ & 11 & 18.3 \\
\hline Mean \pm SD & \multicolumn{2}{|c|}{$4.5 \pm 3.9$} \\
\hline Range & 2 Months - 21 Years & \\
\hline Training Course: & & \\
\hline Yes & 0 & 0.0 \\
\hline No & 60 & 100.0 \\
\hline
\end{tabular}


Table (2): Percent distribution of studied groups' practice about applying capnography:

\begin{tabular}{|c|c|c|c|c|c|c|c|c|c|}
\hline \multirow{4}{*}{ Items } & \multicolumn{8}{|c|}{ Study Group $(\mathrm{n}=60)$} & \multirow{4}{*}{ P-value } \\
\hline & \multicolumn{4}{|c|}{ Pre } & \multicolumn{4}{|c|}{ Post } & \\
\hline & \multicolumn{2}{|c|}{ Done } & \multicolumn{2}{|c|}{ Not Done } & \multicolumn{2}{|c|}{ Done } & \multicolumn{2}{|c|}{ Not Done } & \\
\hline & No. & $\%$ & No. & $\%$ & No. & $\%$ & No. & $\%$ & \\
\hline 1 Hand hygiene & $\overline{45}$ & 75.0 & 15 & 25.0 & $\overline{60}$ & 100.0 & $\overline{0}$ & 0.0 & $0.0001 * * *$ \\
\hline 2 Preparer Equipment: & 17 & 28.3 & 43 & 71.7 & 60 & 100.0 & 0 & 0.0 & $0.0001 * * *$ \\
\hline $\begin{array}{l}3 \text { Obtain order for continuous measuring with } \\
\text { capnography. }\end{array}$ & 17 & 28.3 & 43 & 71.7 & 60 & 100.0 & 0 & 0.0 & $0.0001 * * *$ \\
\hline 4 Assess for proper functioning of capnography & 4 & 6.7 & 56 & 93.3 & 57 & 95.0 & 3 & 5.0 & $0.0001 * * *$ \\
\hline $\begin{array}{l}5 \text { Connect capnography into the appropriate } \\
\text { patient cable into display monitor, and turn on } \\
\text { instrument }\end{array}$ & 14 & 23.3 & 46 & 76.7 & 60 & 100.0 & 0 & 0.0 & $0.0001 * * *$ \\
\hline 6 Perform calibration & 9 & 15.0 & 51 & 85.0 & 60 & 100.0 & 0 & 0.0 & $0.0001 * * *$ \\
\hline $\begin{array}{l}7 \text { If the patient is not intubated, apply pectco } 2 \\
\text { nasal cannula and connect to capnography. }\end{array}$ & 9 & 15.0 & 51 & 85.0 & 58 & 96.7 & 2 & 3.3 & $0.0001 * * *$ \\
\hline $\begin{array}{l}8 \text { For intubated patients, assemble airway } \\
\text { adapter, sensor, and display monitor and connect } \\
\text { to the patient circuit }\end{array}$ & 7 & 11.7 & 53 & 88.3 & 54 & 90.0 & 6 & 10.0 & $0.0001 * * *$ \\
\hline $\begin{array}{l}9 \text { Ensure that the light source is on top of the } \\
\text { circuit }\end{array}$ & 5 & 8.3 & 55 & 91.7 & 58 & 96.7 & 2 & 3.3 & $0.0001 * * *$ \\
\hline $\begin{array}{l}10 \text { Set appropriate alarms. Alarm limits should } \\
\text { in cloud respiratory rate, apnea default, high and } \\
\text { low petco2, and minimal levels of inspiratory } \\
\mathrm{CO} 2\end{array}$ & 2 & 3.3 & 58 & 96.7 & 47 & 78.3 & 13 & 21.7 & $0.0001 * * *$ \\
\hline 11 Discard supplies & 2 & 3.3 & 58 & 96.7 & 30 & 100.0 & 30 & 50.0 & $0.0001 * * *$ \\
\hline 12 Hand hygiene & 38 & 63.3 & 22 & 36.7 & 47 & 78.3 & 13 & 21.7 & 0.072 \\
\hline
\end{tabular}

On-way-ANOVA test

* Statistical significant differences $(p<0.05)$

Table (3): relation between Pre- study groups' socio-demographic data and practice.

\begin{tabular}{|c|c|c|c|c|c|c|c|}
\hline \multirow{3}{*}{ Items } & \multicolumn{6}{|c|}{ Pre group $(n=60)$} & \multirow{3}{*}{ P-value } \\
\hline & \multicolumn{2}{|c|}{ Poor - No. (48) } & \multicolumn{2}{|c|}{ Moderate - No. (12) } & \multicolumn{2}{|c|}{ Good - No. (0) } & \\
\hline & No. & $\%$ & No. & $\%$ & No. & $\%$ & \\
\hline \multicolumn{7}{|l|}{ Age: } & \multirow{3}{*}{0.039} \\
\hline $20 \mathrm{Y}$ to $<35 \mathrm{Y}$ & 47 & 82.5 & 10 & 17.5 & 0 & 0.0 & \\
\hline $35 \mathrm{Y}$ to $<50 \mathrm{Y}$ & 1 & 33.3 & 2 & 66.7 & 0 & 0.0 & \\
\hline \multicolumn{7}{|l|}{ Working place: } & \multirow{4}{*}{0.699} \\
\hline Surgical Major operation & 15 & 75.0 & 5 & 25.0 & 0 & 0.0 & \\
\hline General ICU & 17 & 85.0 & 3 & 15.0 & 0 & 0.0 & \\
\hline Critical Care Unit & 16 & 80.0 & 4 & 20.0 & 0 & 0.0 & \\
\hline \multicolumn{7}{|l|}{ Gender: } & \multirow{3}{*}{0.577} \\
\hline Female & 41 & 78.8 & 11 & 21.2 & 0 & 0.0 & \\
\hline Male & 7 & 87.5 & 1 & 12.5 & 0 & 0.0 & \\
\hline \multicolumn{7}{|l|}{ Educational Level: } & \multirow{5}{*}{$0.046^{*}$} \\
\hline Nursing Diploma & 6 & 60.0 & 4 & 40.0 & 0 & 0.0 & \\
\hline Nursing Technician Institute & 28 & 90.3 & 3 & 9.7 & 0 & 0.0 & \\
\hline Bachelor of Nursing & 6 & 54.5 & 5 & 45.5 & 0 & 0.0 & \\
\hline Institute of Technical healthy & 8 & 100.0 & 0 & 0.0 & 0 & 0.0 & \\
\hline \multicolumn{7}{|l|}{ Years of experience: } & \multirow{5}{*}{$\begin{array}{c}0.0001 \\
* * * *\end{array}$} \\
\hline$<1 \mathrm{Y}$ & 6 & 85.7 & 1 & 14.3 & 0 & 0.0 & \\
\hline $1 \mathrm{Y}$ to $<5 \mathrm{Y}$ & 37 & 90.2 & 4 & 9.8 & 0 & 0.0 & \\
\hline $5 \mathrm{Y}$ to $<10 \mathrm{Y}$ & 1 & 100.0 & 0 & 0.0 & 0 & 0.0 & \\
\hline$\geq 10 \mathrm{Y}$ & 4 & 36.4 & 7 & 63.6 & 0 & 0.0 & \\
\hline \multicolumn{7}{|l|}{ Training Course: } & \multirow{2}{*}{-} \\
\hline No & 48 & 80.0 & 12 & 20.0 & 0 & 0.0 & \\
\hline
\end{tabular}


Table (4) : Percentage distribution of the studied groups regarding their practice level pre \& post.

\begin{tabular}{|c|c|c|c|c|c|c|c|}
\hline \multirow{3}{*}{ Practice Level } & \multicolumn{6}{|c|}{ Study group $(n=60)$} & \multirow{3}{*}{ P-value } \\
\hline & \multicolumn{3}{|c|}{ Pre } & \multicolumn{3}{|c|}{ Post } & \\
\hline & N. & $\%$ & Mean \pm SD & $\mathbf{N}$. & $\%$ & Mean \pm SD & \\
\hline Poor & 48 & 80.0 & $1.7 \pm 1.3$ & 0 & 0.0 & - & \multirow{4}{*}{$\begin{array}{c}0.0001 \\
* * *\end{array}$} \\
\hline Fair & 12 & 20.0 & $6.9 \pm 0.7$ & 2 & 3.3 & $7.0 \pm 0.0$ & \\
\hline Good & 0 & 0.0 & - & 58 & 96.7 & $10.9 \pm 0.9$ & \\
\hline Total & 60 & 100.0 & $2.8 \pm 2.4$ & 60 & 100.0 & $10.8 \pm 1.1$ & \\
\hline
\end{tabular}

* Statistical significant differences $(p<0.05)$

Table (5): Pearson correlation coefficients to evaluate the effect of knowledge on practice according working place.

\begin{tabular}{|l|c|}
\hline \multicolumn{1}{|c|}{ Pearson correlation coefficients } & Knowledge \\
\hline Practice & $\mathbf{0 . 5 4 6}^{*}$ \\
\hline
\end{tabular}

$P$-values for the correlation: $\quad * * P<0.01 \quad \& \quad * P<0.05$

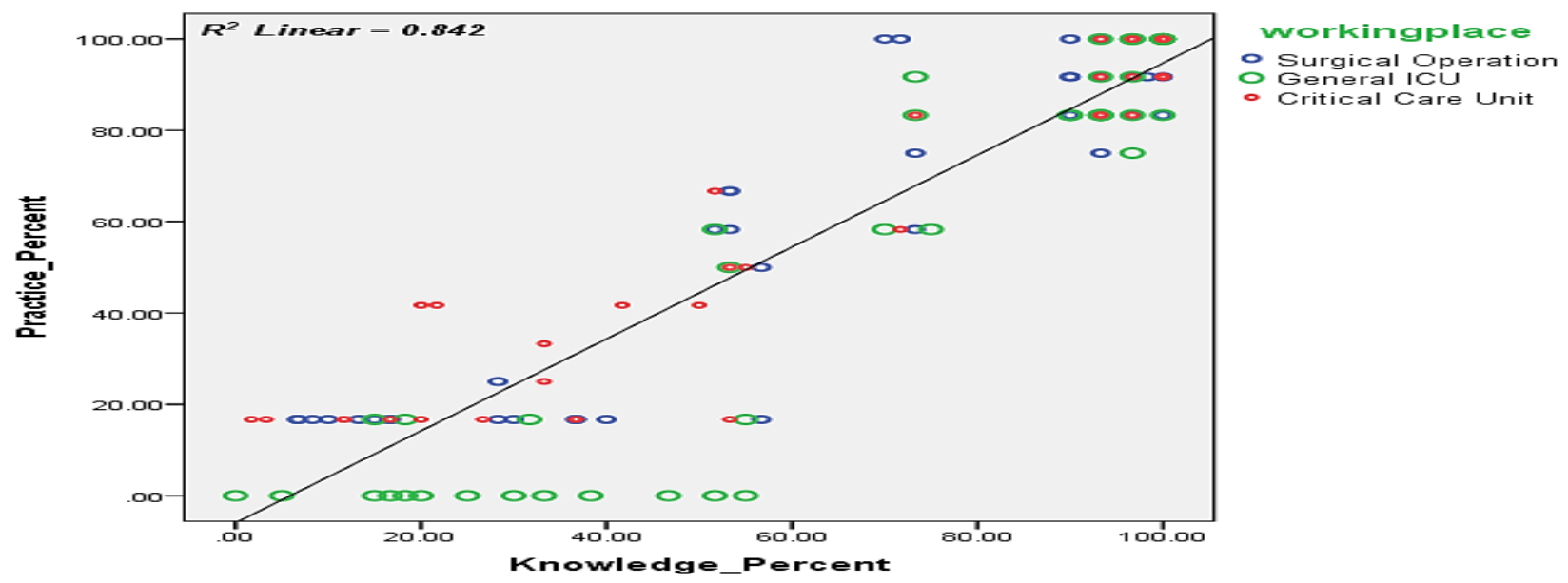

Figure (1): Correlation between Knowledge \& practice.

Table (1): Shown the socio-demographic of studied group: It was found that Vast majority of group was aged from $20 \mathrm{y}$ to $<35 \mathrm{y}$ with percentage $(95 \%)$ and aged from $35 \mathrm{y}$ to $<50 \mathrm{y}$ with percentage $(5 \%)$, Vast majority of gender group were female with percentage $(86.7 \%)$, male with percentage $13.3 \%$. Concerning of experience level of group $11.7 \%$ were from $(<1 \mathrm{Y})$, More than half of group with percentage $(68.3 \%)$ of $1 \mathrm{y}$ to $<5 \mathrm{y}$ of nurses had work experience less than 5 years, $(1.7 \%)$ had more than 10 years. Concerning their educational level Clear majority of group had a Health Technician Institute of level of education with percentage (51.7\%). (16.7\%) of nurses held 3 years nursing diploma, (32\%) held technical institute of nursing, (18.3\%) held Bachelor of nursing and $(13.3 \%)$ held technical health institute of nursing. In relation to their previous training about measuring End-Carbon dioxide by capnography this table reveals that $(100.0 \%)$ of them did not receive any training.
Table (2): Relation between Pre- study groups' sociodemographic data and practice shown that: it was no statistical difference between post-study knowledge and socio- demographic characteristics except Educational Level P-value $0.042 *$ it was statistical difference between post-study knowledge and Educational Level and Years of experience P-value $0.043^{*}$

Table (3): Percentage distribution of the studied groups regarding their practice level pre \& post this table showed that: It was found very highly statistical difference between groups' practice between pre-studied and post-studied groups. Prestudied groups. Pre - practice had Poor level $80.0 \%$ mean, faire $20.0 \%$, Post studied group had Postpractice, practice Post studied group had moderate $3.3 \%$, and had good level with percentage $(96.7 \%)$.

Table (4): Percent distribution of studied groups' practice about applying Capnography this table reflect that: All of items of groups' practice (pre-study $\&$ post-study) had very highly statistical difference, 
except items of groups' practice (pre-study \& poststudy) hand hygiene had no statistical difference.

Table (5): Pearson correlation coefficients to evaluate the effect of knowledge on practice according working place showed that: There was improvement in post-study practice by increasing the Knowledge.

Figure (1): Correlation between Knowledge \& practice it illustrated that there was positive correlation between total nurse knowledge and total practice regarding to working place.

\section{Discussion}

Measurement of end-tidal of carbon dioxide level was a non-invasive method, recommended in the advanced cardiovascular life support resuscitation guidelines of the American Heart Association for monitoring the resuscitation process for patients with cardiac arrest (Chun \& et al., 2016).

Nurses have an important role in measurement of end-tidal of carbon dioxide level Nurses have an ability to assess end-tidal of carbon dioxide waveforms helps distinguish equipment malfunction from changes in the patient's condition (Cynthia, 2018).

Socio-demographic of studied group: The study result revealed that vast majority of group was nursing technician institute, vast majority of gender group were female Concerning their educational level Clear majority of group had a Health Technician Institute of level of education. In relation to their previous training about measuring End-Carbon dioxide by capnography this table reveals that $(100.0 \%)$ of them did not receive any training. this finding was not agreement with (Rafal, 2018) The study group Most of participants male, the analysis shows that the rescuers who declared participation in the training of monitoring and analysis end expiratory value of carbon dioxide, significantly higher correct answers than the staff who did not have such training. However, only $35 \%$ of participants took part in such training in last year. And Study showed agreement of a lack of knowledge and experience in use of devices to measure end expiratory carbon dioxide concentration (EtCO2).

In the current study was found very highly statistical difference between groups' knowledge between prestudied and post-studied groups., agreement with this finding (Mohamed, 2017) shown that, it was found highly statistical difference between groups' knowledge between pre-studied and post-studied groups.

Concerning the effect of the intervention program, the findings of the present study it was found very highly statistical difference between groups' statistically significant improvement in nurses' knowledge and practice regarding capnography device this was noticed immediately after program implementation in comparison to pretest to fulfill the hypotheses I,II .This improvement may be due to many reasons as knowledge refreshment through the program session, this finding was not agreement with For the training program, all nurses participated have taken booklet for program objective and content as well as sufficient materials and supplies were provided for training and not provided at actual work situation. These results were congruent with (Ahmed \& Dutta, 2016) who reported that knowledge and practice level of nurses significantly improved after the teaching program, also congruent with found teaching program were significantly influenced the participants Practice and in the same line (Mohamed \& Wafa, 2011) stated that there was positive statistically correlation between the score of nurses practice and knowledge pre and post implementation program.

The present study: IT was no statistical difference between post-study knowledge and sociodemographic characteristics except Educational Level P-value 0.042 it was statistical difference between post-study knowledge and Educational Level and Years of experience P-value 0.043 this finding was not agreement with( Kiekkas \& et al., 2016) the presence of knowledge deficits amongst this group. This poor knowledge and practice could possibly be attributed to both deficiencies in undergraduate nursing curricula and the lack of continuing education programs for nurses employed in Greek hospitals. Of further importance was the identification of specific knowledge deficits, since participants' correct responses were in the majority of items covering conditions affecting etCO2 and in half items covering indications for capnography use. These findings not only highlight the need for implementing educational programs about capnography, but can appropriately guide these programs to focus on personnel's knowledge deficiencies as well.

The current study finding revealed that there was statistically significant correlation between total nurses' knowledge and skills which indicates Positive relation between knowledge and skills, to fulfill the hypotheses III. This study finding was congruent with (Akinci \& et al., 2014) Findings related to positive correlation between cardiac outputs. The increases in the pulmonary perfusion followed by the initiation chest compressions result in increased that a good indicator for the quality of the cardio pulmonary resuscitation. A rapid increase in PetCO2 value is thought to show the return of spontaneous circulation. Present study: It was no statistical difference between pre-study practice and socio-demographic 
characteristics except Educational Level: It was statistical difference between pre-study practice and teaching Level P-value 0.046*and very highly statistical difference with Years of experience Pvalue 0.0001, disagreement of these result: (Adams \& et al., 2015) there was a significant mean difference of 41.07 points on the Conditions Affecting Capnography Waveform from preintervention. This means that the intervention raised knowledge of the conditions affecting capnography waveform. Finally, there was a significant mean difference of the Indications for Capnography Use from pre-intervention to post-intervention. This means that the intervention raised knowledge of the indications for capnography uses.

\section{Conclusion}

Based on the results of this study, it could be concluded that: The majority of nurses had good level knowledge and practice toward measuring EndCarbon dioxide by Capnography after applying teaching program more than before implementing it with very high statistical significant differences between pre - post teaching program.

\section{Recommendation}

_ Provide teaching and training program for critical care nurses regarding measuring End-Carbon dioxide by Capnography should be available in a written format in critical units and all emergency units.

\section{References}

1. A Seeger C., Higgins C., \& Clevin L., (2014): acute care testing handbook, ISBN 978-8791026-14-0, pp: 80:81, acute care testing handbook .org.

2. Abd El-Aziz A., January (2014): effect of teaching program on nurse's knowledge and skills about oral care for traumatized patients, AL-Azhar Assiut Medical Journal, AAMJ, Vol (12), No (1), 34-35.

3. Aboalizm S., \& Abdel Aziz Kasemy Z., (2016): nurses' knowledge, attitude and practice toward mouth hygiene among critical ill patients , Vol. 3, Issue 3, pp: 1-15.Available at: www.noveltyjournals.com.

4. Antonio M., (2016): Noninvasive Mechanical Ventilation and Difficult Weaning in Critical Care, N: 6, pp: vii, pdf available: www.springer.com

5. Boulos S., Nassar M., \& Gregory A., (2016): Critical Care Medicine, C H E S T, Capnography during Critical Illness, volume:149,N:(2),PP: 576:585, publication at: https://www.researchgate.net/publication/28276 4403.

6. Craig D., \& Brian K., (2017): RESPIRATORY CARE Noninvasive Monitoring of Oxygen and Ventilation, VOL: 62. N: 6, pp: 751-764.

7. Elizabeth T., Chad A., Sheri L., Carolyn B., Nancy B., \& Patricia B., (2015): Nursing: Scope and Standards of Practice, volume3, N: 13, pp: 26 available at: http://www.Nursesbooks.org.

8. Janice J., Brenda F., (2015): Critical Care Notes Clinical Pocket Guide, volume: 2, N: 2 1, pp: 5:6.

9. Jeffrey C., Gershe E., Sandra J., \& James A., (2018) Clinical Manual of Emergency Pediatrics, volume 6, N: 6, pp: xvi at: www.cambridge.org.

10. Jonathan B. Waugh P, Donna D, Gardner M, 2013, Effect of Heliox on End-tidal CO2 Measurement in Healthy Adults N: 7,

11. Linda A., \& Silver S., (2017): the Nclex examination, professional nurse, acid-base balance, respiratory system $\mathrm{c} h$ a $\mathrm{p} \mathrm{t}$ e $\mathrm{r} 3$, volume7, N: 51-, pp: 30:97/708:709.

12. Linda D., Kathleen M., Mary E., (2016): Priorities on Critical Care nursing, volume: 7, pp: 301:303.

13. Linda D., Urden (2014): critical care nursing, Diagnosis and Management, Critical Care Nursing Practice, unit 1 foundation of critical care,pp:2 volume 7 pdf available at http://evolve.elsevier.com/Urden/criticalcare/.

14. Marc A., Russo1., Danielle M., Santarelli 1., \& Dean O., (2017): Breathe, Volume: 13, No 4, pp: 298.

15. Mary F., Joanna L., Stollings P., Sarah L., Bloom A., Elizabeth L., Huggins A., Scottie L., Grayson C., Jackson P., \& Carla M., (2016): AACN Advanced Critical Care Volume 27, Number 2, pp.157, 238.

16. Matthew G., Carl L., \& John W., (2017): Clinical Anesthesia Lecture Notes N: 52, volume 5, pp: 25.

17. Noor S., Ramadan H., \& Yousif K., (2016): Effect of Health Educational Program On Nurses Knowledge \& practice Regarding Infection Control in Neonatal Intensive Care Unit at Pediatric Hospitals in Khartoum State (Sudan 2016),pp:42

18. Paula D., Mike M., Evoy R., \& Jon T., (2014): Emergency \& Critical Care Pocket Guide ADVANCED CARDIOVASCULAR LIFE SUPPORT Version, volume: 8, N: 48, pp: 9:10/40:52. 
19. Sequeira A., (2017): introduction to concepts of teaching and learning, $\mathrm{N}: 66 \mathrm{pp}$ : 3:6, available at: $\mathrm{ttp}: / / \mathrm{ssrn}$.com/abstract $=2150166$.

20. Shawn B., Jones H., Michael L., \& Karen G., (2016): journal of radiology nursing, volum 35 , N: 3, pp: 182:183 available at: www.radiology nursing.org.

21. Sheila A., Sue O., \& John W., (2017): Critical Care Nursing, Science and Practice, $3^{\text {rd }} \mathrm{Ed}$, Oxford University Press, Oxford.pro quest.

22. Shetty S., Hunt K., Peacock J., Ali K., \& Greenough A., (2017): Crossover study of assist control ventilation adjusted ventilatory assist, European Journal of Pediatrics, 176(4):509-513.

23. Tilak D., (2017): Data Interpretation in Anesthesia a Clinical Guide, N: 61, volume: 1, pp: 35:39 /137:140. 